\title{
Endoscopic submucosal dissection: macromolecules or high-pressure injection or both?
}

\section{(6)(1) $\odot$}

\author{
Authors \\ Mathieu Pioche' ${ }^{1}$, Jérémie Jacques ${ }^{2}$ \\ Institutions \\ 1 Hepatogastroenterology division, Edouard Herriot \\ Hospital, Lyon, France \\ 2 Hepatogastroenterology division, Dupuytren Hospital, \\ Limoges, France \\ Bibliography \\ DOI https://doi.org/10.1055/a-0838-5508 | \\ Endoscopy International Open 2019; 07: E583-E584
}

\author{
(c) Georg Thieme Verlag KG Stuttgart · New York \\ ISSN 2364-3722 \\ Corresponding author \\ Mathieu Pioche, MD, PhD, Service de gastro-entérologie et \\ d'endoscopie digestive, Pavillon L, Hôpital Edouard Herriot, \\ 5 place d'Arsonval 69437 Lyon, France \\ Fax: +33472110147 \\ mathieu.pioche@chu-lyon.fr
}

Endoscopic mucosal resection (EMR) is based on the principle of enlarging the submucosal space through injection of fluids. This cushion has the potential to pedunculate flat lesions, but also to keep the muscle away from the cutting line. The main problem with the injection is lack of long-lasting stability during the procedure, with a corresponding progressive decrease in the cushion. Two ideas have been initially evaluated for maintaining good-quality lift: use of viscous solutions with restrained diffusion and in parallel, high-pressure injections that allow for frequent repeated introduction of fluid.

Viscous solutions with restrained diffusion in the submucosal layer have been evaluated for obtaining a long-lasting and stable mucosal cushion [1-3]. Furthermore, it has also been demonstrated that the quality of the viscous mucosal cushion is better with a more rigid bleb, facilitating resections. This stable bleb was associated with safer endoscopic resections [4]. One of the most studied solutions was use of hyaluronic acid because of its viscous power and also its capacity for promoting healing [5]. Nevertheless, hyaluronic acid solution is expensive and its viscosity makes injection through an endoscopy needle difficult. Recently, new solutions such as poloxamers have been developed that have variable viscosity, depending on temperature or pressure. For example, poloxamer 407 is fluid at $20^{\circ} \mathrm{C}$ and then easily injectable through a needle but becomes a gel once injected into the submucosa where the temperature is $37^{\circ} \mathrm{C}$ to make a stable bleb. Fernandez-Esparrach et al described submucosal injection of poloxamer 407 solution for EMR in 2009 [6] and a new work in this issue of Endoscopy International Open [7] underscores the capacity of such solution to facilitate obtaining good histology specimens with less induction of fibrosis. Furthermore, in this animal study, the authors also demonstrated that the healing properties of poloxamer 407 are close to those of hyaluronic acid, making this solution highly suitable for endoscopic resection.

In parallel, it was also demonstrated that repeated injection of saline with high-pressure systems also allowed for maintenance of a good-quality submucosal cushion by facilitating frequent and forceful fluid reinjection. This repeated injection of saline clearly facilitates endoscopic submucosal dissection (ESD) and dramatically reduces risk of perforation with both the Erbe (Tuebingen, Germany) [8] and the Nestis (Lyon, France) [9] high-pressure systems.

A question remained about the benefits of combining both viscous solutions and high-pressure injection. Initially, that was not possible with the Erbe pump system, but it is in fact feasible with low-viscosity fluids like glycerol mix, which result in better ESD outcomes than with saline high-pressure injection [10]. Furthermore, in an animal study, we demonstrated that the Nestis system could be used to inject highly viscous solutions, including hyaluronic acid and also poloxamer 407. Furthermore, our study revealed that a combination of high-pressure injection and viscous solution was more effective, with a $25 \%$ increase in speed for achieving ESD of 3-cm lesions [11]. In fact, viscous solutions tend to maintain tension in the injected area and high pressure improves elevation of the bleb, making a suitable mushroom shape. Thanks to those two effects, high pedunculated shape of a bleb is obtained, which facilitates both snare positioning during EMR and scope insertion in the submucosal space during ESD.

Mucosal lifting is a key factor in endoscopic resections both for EMR and ESD and viscous solutions help to produce a high and stable bleb. Nevertheless, ESD is a difficult technique and every technical trick that facilitates the procedure is welcome. Thus, optimized ESD with high-pressure injection of viscous so- 
lution eventually combined with traction strategies [12] is probably the way forward in promoting widespread use of this technique.

\section{Competing interests}

Dr. Pioche was involved in developing the Nestis system in Lyon and worked for the company in 2013. The company does not exist anymore and was sold to Boston Scientific in 2015. Dr. Pioche has absolutely no link with the actual development of the system.

\section{References}

[1] Fujishiro M, Yahagi N, Kashimura K et al. Comparison of various submucosal injection solutions for maintaining mucosal elevation during endoscopic mucosal resection. Endoscopy 2004; 36: 579-583

[2] Fujishiro M, Yahagi N, Kashimura K et al. Different mixtures of sodium hyaluronate and their ability to create submucosal fluid cushions for endoscopic mucosal resection. Endoscopy 2004; 36: 584- 589

[3] Hyun J], Chun HR, Chun HJ et al. Comparison of the characteristics of submucosal injection solutions used in endoscopic mucosal resection. Scand J Gastroenterol 2006; 41: 488-492

[4] Yamamoto H, Yahagi N, Oyama T et al. Usefulness and safety of $0.4 \%$ sodium hyaluronate solution as a submucosal fluid "cushion" in endoscopic resection for gastric neoplasms: a prospective multicenter trial. Gastrointest Endosc 2008; 67: 830-839
[5] Fujishiro M, Yahagi N, Kashimura K et al. Tissue damage of different submucosal injection solutions for EMR. Gastrointest Endosc 2005; 62: $933-942$

[6] Fernández-Esparrach G, Shaikh SN et al. Efficacy of a reverse-phase polymer as a submucosal injection solution for EMR: a comparative study (with video). Gastrointest Endosc 2009; 69: 1135-1139

[7] Cordova Guevara H, Cuatrecasas M et al. Successful outcomes of Hyaluronic acid, chondroitin sulfate and Poloxamer 407 as submucosal injection solution: animal survival study. Endoscopy International Open 2019; 07: E576-E582

[8] Yahagi N, Neuhaus H, Schumacher B et al. Comparison of standard endoscopic submucosal dissection (ESD) versus an optimized ESD technique for the colon: an animal study. Endoscopy 2009; 41: $340-$ 345

[9] Ciocîrlan M, Pioche M, Lepilliez V et al. The ENKI-2 water-jet system versus Dual Knife for endoscopic submucosal dissection of colorectal lesions: a randomized comparative animal study. Endoscopy 2013; 30: $5140-5146$

[10] Jacques J, Sautereau D, Carrier P et al. High-pressure injection of glycerol with HybridKnife for ESD is feasible and increases the ease and speed of the procedure: an in vivo study in pigs and first use in human. Surg Endosc 2015; 29: 3382 - 3385

[11] Pioche M, Ciocirlan M, Lépilliez V et al. High-pressure jet injection of viscous solutions for endoscopic submucosal dissection: a study on ex vivo pig stomachs. Surg Endosc 2014; 28: 1742 - 1747

[12] Jacques J, Charissoux A, Legros R et al. Double-clip counter-traction using a rubber band is a useful and adaptive tool for colonic endoscopic submucosal dissection. Endoscopy 2017; 50: 179-181 